\title{
Objective Determination of Claw Pain and Its Relationship to Limb Locomotion Score in Dairy Cattle
}

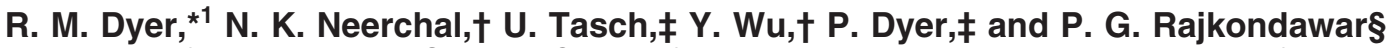 \\ *Department of Animal and Food Sciences, College of Agriculture and Natural Resources, University of Delaware, Newark 19717 \\ †Department of Mathematics and Statistics, and \\ ‡Department of Mechanical Engineering, \\ University of Maryland at Baltimore County, Baltimore 21250 \\ §Bou-Matic LLC, Madison, WI 53708
}

\begin{abstract}
We hypothesized that claw and foot pain could be objectively determined and have a strong effect on limb locomotion. Claw pain was measured using hoof testers equipped with a pressure gauge. Soft tissue pain was evaluated with an algometer. Pain was determined as the maximum pressure recorded at the time the limb was withdrawn following claw or soft tissue compression with the hoof tester or algometer. Locomotion scores and claw and soft tissue pain were determined on 263 Holstein cows from 2 commercial dairy farms. The frequency and the magnitude of pain had an effect on locomotion score in the ipsilateral limb for lateral, but not medial, claws. The magnitude of the lateral claw pain index for limbs with locomotion scores 1 to 5 was $0.95 \pm 0.01,0.90 \pm 0.02,0.67 \pm 0.04,0.65 \pm 0.05$, and $0.45 \pm 0.11$, respectively. The magnitude of the medial claw pain index for limbs with locomotion scores 1 to 5 was $1.0 \pm 0.00,0.99 \pm 0.01,0.98 \pm 0.01,1.0 \pm$ 0.00 , and $1.0 \pm 0.00$, respectively. The frequency of painful claws $(n=208)$ in limbs with locomotion scores 1 , 2 , and $\geq 3$ was $0.529,0.173$, and 0.298 , respectively. The frequency of painless claws $(\mathrm{n}=318)$ in limbs with locomotion scores 1,2 , or $\geq 3$ was $0.792,0.088$, and 0.120 , respectively. The frequency of pain $(27.1 \%)$ and total lesions $(85.6 \%)$ was greater in lateral claws $(\mathrm{n}=524)$ than that of pain $(2.1 \%)$ and total lesions $(14.4 \%)$ in medial claws $(n=524)$. Yet the magnitude of the pain index in sore claws was similar for medial $(0.73 \pm 0.09)$ and lateral claws $(0.64 \pm 0.02)$. The magnitude and frequency of claw pain in one hind limb was inconsistently and weakly affected by locomotion score or claw pain in the contralateral limb. The prevalence of unilateral (32.8\%) and bilateral (23.3\%) pain was similar and lower than the occurrence of bilaterally nonpainful
\end{abstract}

Received January 3, 2007.

Accepted June 7, 2007.

${ }^{1}$ Corresponding author: rdyer@udel.edu claws $(43.9 \%)$ in the study group. Painful claws ( $\mathrm{n}=$ 78 ) occurred on sound limbs $(n=332)$ with a pain index $(0.72 \pm 0.02)$ indicative of less pain than the pain index $(0.61 \pm 0.02)$ of painful claws $(n=130)$ on lame limbs $(\mathrm{n}=192)$. The results showed that lateral claw pain was related to ipsilateral limb locomotion score and subclinical pain was a relatively common occurrence. Objective measures of pain may provide a more reliable, continuous measure of clinical events used in modeling lameness.

Key words: lameness, objective pain determination, claw pain, locomotion score

\section{INTRODUCTION}

Limb and claw health are traditionally evaluated by various schemes of locomotion (Wells et al., 1993; Clarkson et al., 1996; Sprecher et al., 1997) or lesion scoring (Murray et al., 1996). Difficulties with locomotion scoring arise from requirements for observer training (Engel et al., 2003), difficulties in evaluating stride and postural characteristics (Flower and Weary, 2006), low reproducibility in scoring mild lameness (Wells et al., 1993; Engel et al., 2003; Holzhauer et al., 2005), and employment of categorical scales to evaluate disturbances in locomotion better described as a continuum of events.

Although the process is still in its infancy, automated and objective methods of lameness detection from kinetic and kinematic data have been adopted for cattle (Flower et al., 2005; Rajkondawar et al., 2006). Ground reaction forces in the horizontal and vertical dimensions were used to evaluate locomotion characteristics (Van der Tol et al., 2003, 2004). Early kinetic reports indicated vertical and horizontal ground reaction forces inconsistently differed between sound and normal bovine limbs (Scott, 1989). One-dimensional kinetic measurements using a parallel plate system suggested that variability of any single limb movement trait was high enough that no single limb movement trait consistently distinguished sound from lame limbs. Still, an algo- 
rithm incorporating 6 traits generated an index capable of distinguishing lame from sound limbs (Rajkondawar et al., 2006). Kinematic data indicated stride length, stride height, stance duration, hoof speed, and arc of foot flight differed between normal limbs and limbs afflicted with sole ulceration (Flower et al., 2005). Kinematic traits of limbs with minor lesions did not differ from those of sound limbs. Differences in conclusions stemming from the 2 approaches might be attributable to differences between kinematic and kinetic data or how lameness data were incorporated into the models. For example, the kinetic models (Rajkondawar et al., 2006) were generated from data sets including all lame limbs regardless of locomotion or lesion score, whereas the kinematic modeling (Flower et al., 2005) was performed with lameness broken into limbs with sole ulceration, limbs with minor sole lesions, and normal limbs. Modeling lameness is difficult because the most important factor(s) that drive limb locomotion remain undefined. Moreover, even though objective measures of stride and weight bearing are available, their relationship to altered locomotion remains undefined. Recently, we reported that clinical lameness was amenable to automated, objective evaluation with a 1-dimensional force plate system. The modeling process was thought limited by use of subjective, categorical scales of clinical lesions and locomotion (Rajkondawar et al., 2006). Use of continuous scales of clinical information may not resolve the problem. Visual analog scales of locomotion ranging 1 to 100 (Flower et al., 2005) did not improve upon the 1 to 5 numerical scaling system for lameness scoring. These results are in accord with others, where a visual analog scale of lesion severity scores ranging 1 to 100 explained only $47 \%$ of the variability in locomotion score (Whay et al., 1997). We hypothesized that pain would be an important determinative factor of disturbances in limb locomotion and therefore highly related to locomotion score. The objective was to assess the subjectivity of clinical data and develop methods of objective pain measurement in the bovine foot. Furthermore, we proposed that locomotion would be affected by the magnitude of claw pain, its frequency, or both.

\section{MATERIALS AND METHODS}

\section{Cows and Production Units}

The research protocol was approved by the Animal Care and Use Committees for the University of Maryland at Baltimore County and the University of Delaware.

Data were generated from cows in 2 commercial dairy herds consisting of 550 and 1,450 lactating Holstein dairy cows. The cows were housed in free-stall barns with retractable curtains. Stalls in both herds consisted of rubber mats overlaid with wood shavings. Floors were grooved cement with rubber mats in front of the feed bunk in one herd and slatted floors in the other herd. Cows in both herds were fed a TMR 3 times daily formulated to meet lactation requirements of a $660-\mathrm{kg}$ cow producing $38 \mathrm{~kg}$ of $3.5 \% \mathrm{FCM}$ per day (NRC, 2001). Cows were milked 3 times daily in herds and feet were trimmed 2 to 3 times/yr by professional hoof trimmers. Lactating cows ( $n=15$ to $18 /$ wk per farm) from each herd were randomly selected by a number generator without regard to locomotion status, production, or parity. Data included 127 and 135 cows from each of the farms, respectively.

\section{Data Collection}

Locomotion scores were established for each cow by a single veterinarian as previously described by Rajkondawar et al. (2006) and modified from Sprecher et al. (1997), Clarkson et al. (1996), and Wells et al. (1993). Once weekly, cows were observed at a stance and then while walking in a straight line. To facilitate identification of lame limbs, cows were circled to the right and to the left. All examinations on both farms were performed in an alleyway of solid concrete flooring free of slurry and lightly covered with dry wood shavings. Locomotion observations were performed by viewing the animal perpendicular, parallel, posterior, and anterior to the line of travel. During locomotion evaluation, cows and limbs were observed for freedom of motion, left- and right-sided stride length, length of anterior and posterior swing phases, symmetry and arc of the foot flight, foot placement relative to body position and limb axis, foot rotation during weight bearing, symmetry of weight distribution at the walk and stance, and position of top line at a walk and stance. A score of 1 to 5 was assigned for each limb (Table 1). To score 2 limbs on the same cow, the lamer of the 2 limbs was assigned the locomotion score (Table 1) normally assigned to the cow. The unscored, second limb was assigned the same score or a lower score from Table 1 depending upon the relative level of locomotion changes displayed in the second limb.

Cows were placed in a chute equipped with a head gate and a manually operated rope foot lift (farm 1). Pain evaluation, trimming, and lesion diagnosis followed limb restraint by manually elevating the limb with a rope fastened mid-diaphysis of the third metatarsal bone. In farm 2, cows were placed on a hydraulic table and positioned into lateral recumbency. All 4 limbs were fastened onto the table with rope positioned mid-diaphysis of the third metatarsal or metacarpal bone. In all cases, restraints allowed limb movement of approximately 20 to $30 \mathrm{~cm}$. All feet were cleansed 
Table 1. Method for assigning a locomotion score; an adaptation of the methods of Sprecher et al. (1997), Clarkson et al. (1996), and Wells et al. (1993)

\begin{tabular}{lcc}
\hline Classification & $\begin{array}{c}\text { Locomotion } \\
\text { score }\end{array}$ & $\begin{array}{c}\text { Locomotion characteristics } \\
\text { Sound }\end{array} \quad 1 \quad \begin{array}{c}\text { Cows walk freely with unrestricted motion and symmetry in the stride. No postural abnormalities } \\
\text { are exhibited. }\end{array}$ \\
Mildly lame & 2 & $\begin{array}{c}\text { No visible locomotion abnormality, but an arched top line develops with the walk. Top line may be } \\
\text { normal or arched and stride length may be slightly shortened on the inside limb during circling. } \\
\text { The locomotion is tentative and the top line is arched at a walk and a stance. Abnormalities in } \\
\text { locomotion are apparent at a straight walk and do not require circling to become visible. } \\
\text { Cows are reluctant to rise and do so with difficulty. Weight bearing at a stance is distributed } \\
\text { asymmetrically with reluctance to move and bear weight on the affected limbs. The top line is } \\
\text { profoundly arched at a stance and walk and the locomotion is tentative and slow. } \\
\text { Cows are unable or unwilling to rise, move, or bear weight on the affected limb(s). The limb is } \\
\text { held off the ground, gently rested on the ground, or carried in a fixed position. }\end{array}$ \\
Severely lame & 4 &
\end{tabular}

and trimmed to remove stained, overgrown hoof horn tissue following guidelines of Toussaint-Raven (1985). All lesions were diagnosed in accord with Rajkondawar et al. (2006), scored for severity, measured to determine size, and photographed (data not shown).

\section{Pain Evaluation}

Claw pain was determined by compression using a hoof tester designed to transfer compression forces through a Dillon force gauge (Model X 250, Dillon Force Measurement Products and Systems, Fairmont, MN). Cows were initially adapted to the process of hoof compression by gentle application of pressure 4 to 5 times along an axis extending from the dorsal wall to the sole across regions 3, 4, and 5 (Shearer et al., 2004) and then along the axial-abaxial axis across regions $3,4,5$, and 6. Ultimately, pain determinations were performed along the axis extending between abaxial and axial walls, because no differences in results occurred between the 2 axes of application (data not shown). Increasing amounts of claw compression were applied to attain $711.68 \mathrm{~N}$ of force or until the cow no longer tolerated the compression by showing a withdrawal response. This force generated a pressure of $459.74 \mathrm{~N} /$ $\mathrm{cm}^{2}\left(\mathbf{P}_{\max }\right)$ atjunction of the hoof and the arm of the hoof tester. Pressure attained at the onset of foot withdrawal $\left(\mathbf{P}_{\mathbf{i}}\right)$ was recorded only after animals reacted to 3 repeated compression tests along the same axis. Compression was always performed on the medial claw first followed by the lateral claw. Claw compression tests were always repeated in triplicate for both medial and lateral claws. Whenever animals with locomotion scores of 1 demonstrated an apparently reproducible painful compression test, the test was repeated in triplicate a second time.

To evaluate the effect of claw trimming on pain measurements, pain responses were determined on claws with and without lesions, before and after trimming.
Pain responses were determined immediately before and then immediately after trimming. Pain indices (PICLAW) were calculated as $\mathrm{P}_{\mathrm{i}} / \mathrm{P}_{\max }$, where $\mathrm{P}_{\mathrm{i}}$ was the pressure recorded upon limb withdrawal and $\mathrm{P}_{\max }$ was $459.74 \mathrm{~N} / \mathrm{cm}^{2}$ pressure; $\mathrm{P}_{\mathrm{i}} / \mathrm{P}_{\max }$ was therefore dimensionless.

Pain associated with lesions of the integument was assessed using an algometer (44.48 $\mathrm{N}$ scale) with a blunt probe (Wagner Force Dial FDK10, Wagner Instruments, Greenwich, CT) pressed against the integument. The probe was placed on the lesion surface or on the junction of the interdigital and plantar surfaces of the volar integument. Increasing levels of force were applied to the integument or lesion to attain $44.48 \mathrm{~N}$ of force or until the cow had a withdrawal response. The force of $44.48 \mathrm{~N}$ resulted in a pressure of 140.54 $\mathrm{N} / \mathrm{cm}^{2}$. Pressure attained at the onset of foot withdrawal was recorded only after animals reacted to 3 repeated pressure tests. Integumental pain indices were calculated as $\mathrm{P}_{\mathrm{i}} / \mathrm{P}_{\max }$, where integumental $\mathrm{P}_{\mathrm{i}}$ was the pressure recorded upon limb withdrawal and integumental $\mathrm{P}_{\max }$ was $140.54 \mathrm{~N} / \mathrm{cm}^{2}$. The final PICLAW was determined as the smaller $\mathrm{P}_{\mathrm{i}} / \mathrm{P}_{\max }$ of the claws and integument.

\section{Statistical Methods}

Statistical methods used were ANOVA, $\chi^{2}$, and Fisher's least significant difference method for pairwise comparisons (Zar, 1994). To investigate the hypothesis that claw pain and locomotion scores were related, limbs were grouped by locomotion scores and compared with group mean claw pain values. The underlying statistical model was as follows:

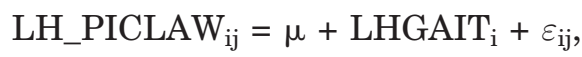

where the LH_PICLAW denotes the claw pain index for jth left limb in the ith ( $i=1,2$, or 3 ) group of locomo- 
Table 2. Lesion distribution by lesion type within both pelvic limbs and by lateral and medial claws of the pelvic limb

\begin{tabular}{|c|c|c|c|c|c|c|}
\hline \multirow[b]{2}{*}{ Lesion type } & \multicolumn{2}{|c|}{$\begin{array}{l}\text { Left and right } \\
\text { hind limbs }\end{array}$} & \multicolumn{2}{|c|}{ Lateral claw } & \multicolumn{2}{|c|}{ Medial claw } \\
\hline & $\mathrm{n}$ & $\%$ & $\mathrm{n}$ & $\%$ & $\mathrm{n}$ & $\%$ \\
\hline Hemorrhage & 146 & 26.7 & 119 & 32.3 & 27 & 43.6 \\
\hline White line disease & 123 & 22.5 & 104 & 28.2 & 19 & 30.7 \\
\hline Sole ulcer & 91 & 16.6 & 85 & 23.0 & 6 & 9.7 \\
\hline Subsolar abscess & 36 & 5.6 & 34 & 9.2 & 2 & 3.2 \\
\hline Double sole & 13 & 2.4 & 11 & 3.0 & 2 & 3.2 \\
\hline Bruise & 22 & 4.0 & 16 & 4.3 & 6 & 9.7 \\
\hline Fibroma & 17 & 3.1 & - & - & - & - \\
\hline Tibial tarsal joint & 30 & 5.5 & - & - & - & - \\
\hline Digital dermatitis (hairy wart) & 8 & 1.5 & - & - & - & - \\
\hline Interdigital dermatitis & 60 & 11.0 & - & - & - & - \\
\hline Pododermatitis & 1 & 0.2 & - & - & - & - \\
\hline Total & 547 & 100 & 369 & 100 & 62 & 100 \\
\hline
\end{tabular}

tion score, $\mu$ is the overall mean, LHGAIT $_{i}$ is the ith $\mathrm{LH}$ gait score, and $\varepsilon_{\mathrm{ij}}$ denotes the noise associated with the ijth observation. Validity of the ANOVA model was based upon independence $(n=263$ cows $)$ of observation and the data were Gaussian (Zar, 1994). In all comparisons, sample sizes were clearly presented to show that differences existed in sample size by treatments.

The data set contained a large number of cows (115) with no pain in either limb. Therefore, the PICLAW values for a large percentage of observations were clustered at 1 . Because ANOVA was an inappropriate analytic method for such data, methods of categorical data analysis $\left(\chi^{2}\right)$ were used to demonstrate associations between locomotion score and level of pain (Zar, 1994). Categorical analysis was used to demonstrate associations between lesions prevalence and pain response in trimmed or untrimmed claws. An ANOVA was used to evaluate the hypothesis that claw pain was greater in cows with bilateral rather than unilateral lameness. The PICLAW was determined from all unilaterally lame cows grouped into a single group and compared by ANOVA to the ipsilateral PICLAW of all bilaterally lame cows from the same table.

\section{RESULTS}

The distribution of lesion type in the pelvic limb (Table 2) showed that sole hemorrhage, white line disease, and sole ulceration accounted for $65.8 \%$ of all diagnoses in the hind limb. Interdigital pathology accounted for $15.7 \%$ of all hind limb lesions.

Pain occurred more frequently in lateral claws $(27.10 \%, \mathrm{n}=524)$ compared with medial claws $(2.10 \%$, $\mathrm{n}=524 ; P<0.001)$. Lesion distribution by claw within pelvic limb showed that $85.6 \%$ of all claw lesions $(\mathrm{n}=$ 369 ) occurred in the lateral claw and $14.4 \%$ occurred in the medial claw (Table 2). Hemorrhage, sole ulcer, and white line disease accounted for the greatest proportion of claw lesions. The distribution of lesion types differed $(P=0.025)$ between claws, because sole ulceration and subsolar abscess accounted for a greater proportion of the lesions in lateral compared with medial claws.

Presence of claw lesions affected pain responses in trimmed or untrimmed claws (Table 3). Lesion prevalence was greater in claws where pain detection was enhanced with trimming compared with claws where trimming did not enhance pain responses $(P<0.01)$. Trimming claws with few or no lesions (Table 3 ) did not affect hoof pressure responses, because differences in pressure responses before and after trimming were $2.67 \pm 7.44 \mathrm{~N} / \mathrm{cm}^{2}(\mathrm{n}=26)$. In contrast, trimming claws with a high number of lesions (Table 3 ) affected hoof pressure responses. Withdrawal responses required $114.15 \pm 87.35 \mathrm{~N} / \mathrm{cm}^{2}(\mathrm{n}=28)$ less pressure after removal of excess horn overgrowth compared with pressure requirements before trimming. Lesions in 16 claws that were deemed nonpainful $\left(\mathrm{P}_{\mathrm{i}}=1\right)$ before trimming were judged as painful $\left(\mathrm{P}_{\mathrm{i}}<1\right)$ after trimming. Thus, claw trimming decreased the pressure required to elicit withdrawal responses in claws with lesions. Accord-

Table 3. Lesion distribution across trimming effect and pain detection

\begin{tabular}{lrcrrr}
\hline & \multicolumn{2}{c}{$\begin{array}{c}\text { Pretrim pressure } \\
\text { posttrim pressure } \\
\left(459.74 \text { N/cm }{ }^{2}\right)\end{array}$} & & \multicolumn{2}{c}{$\begin{array}{c}\text { Posttrim pressure } \\
<\text { pretrim pressure }\end{array}$} \\
\cline { 2 - 3 } \cline { 5 - 6 } Lesion & $\mathrm{n}$ & Severity score & & $\mathrm{n}$ & Severity score \\
\hline Hemorrhage & 11 & 3.36 & & 10 & 3.90 \\
White line & 5 & 2.40 & & 9 & 2.78 \\
Sole ulcer & 3 & 2.00 & & 12 & 3.20 \\
Abscess & 0 & 0 & & 6 & 3.83 \\
Double sole & 0 & 0 & & 2 & 5.00 \\
None & 10 & 0 & & 2 & 0 \\
\hline
\end{tabular}


Table 4. Summary statistics for PICLAW ${ }^{1}$ by locomotion score across claws for all lateral and medial claws

\begin{tabular}{|c|c|c|c|c|c|c|c|c|}
\hline \multirow{2}{*}{$\begin{array}{l}\text { Locomotion } \\
\text { score }\end{array}$} & \multicolumn{4}{|c|}{ Lateral claw } & \multicolumn{4}{|c|}{ Medial claw } \\
\hline & $\mathrm{n}$ & Mean & SD & $\mathrm{CV}(\%)$ & $\mathrm{n}$ & Mean & $\mathrm{SD}$ & $\mathrm{CV}(\%)$ \\
\hline 1 & 332 & $0.95^{\mathrm{b}}$ & 0.14 & 14.38 & 332 & $1.00^{\mathrm{a}}$ & 0.03 & 2.77 \\
\hline 2 & 90 & $0.90^{\mathrm{bc}}$ & 0.16 & 17.63 & 90 & $0.99^{\mathrm{ab}}$ & 0.04 & 3.83 \\
\hline 3 & 55 & $0.67^{\mathrm{a}}$ & 0.30 & 44.34 & 55 & $0.98^{\mathrm{b}}$ & 0.06 & 5.83 \\
\hline 4 & 38 & $0.65^{\mathrm{a}}$ & 0.28 & 42.39 & 38 & $1.00^{\mathrm{ab}}$ & 0.03 & 3.06 \\
\hline 5 & 9 & $0.45^{\mathrm{d}}$ & 0.32 & 71.29 & 9 & $1^{\mathrm{ab}}$ & 0 & 0 \\
\hline
\end{tabular}

${ }^{a-d}$ Different superscripts indicate that values within columns differed significantly $(P<0.05)$.

${ }^{1}$ PICLAW = claw pain index (dimensionless).

ingly, all pain responses were performed before trimming to evaluate claw pain under identical conditions of locomotion scoring.

\section{Changes in the Magnitude of PICLAW are Related to Changes in Locomotion Score}

Pain indices across 5 locomotion scores for all medial and all lateral claws (Table 4) affected locomotion scores within lateral, but not medial, PICLAW $(P<0.001)$. Pressure eliciting a withdrawal reaction decreased with increasing limb locomotion score because the lateral PICLAW decreased with worsening locomotion. The negative effect of PICLAW on locomotion score was most evident in the lateral claw and least evident in the medial claws. The data showed that the degree of uncertainty was larger for cows with locomotion scores 3,4 , and 5 . The coefficient of variation $(\mathbf{C V})$ for the lateral claws ranged between 14.4 and $17.6 \%$ for limbs with locomotion scores 1 and 2, but increased 3- to 4fold in cows with locomotion scores of 3,4 , and 5. For the medial claws, the largest CV was approximately $5.8 \%$ for score 3 (Table 4). This was not surprising because very few medial claws were painful or affected with lesions.

We evaluated the effect of limb locomotion on the magnitude of PICLAW within the subset of lateral painful claws $(n=183$; Figure 1$)$. The set of painful medial claws was too small for meaningful analysis. Similar to PICLAW within all claws, the magnitude of PICLAW for painful claws had an effect on locomotion score $(P$ $<0.001$; Figure 1). Painful claws were clearly more painful at higher scores of locomotion. Even though visible locomotion disturbances were not apparent, the mean magnitude of PICLAW was reduced $(P=0.003)$ below 1 in painful claws on limbs with locomotion scores 1 $(\mathrm{n}=68)$ and $2(\mathrm{n}=42)$. Moreover, PICLAW across limbs lacking visible locomotion abnormalities (locomotion scores 1 and 2$)$ was different $(P<0.05)$ than PICLAW for limbs with visible locomotion abnormalities (scores $\geq 3)$. The PICLAW $(0.64 \pm 0.23)$ within all painful lateral claws $(\mathrm{n}=183)$ was not different from PICLAW $(0.73$ \pm 0.34 ) within all painful medial claws $(\mathrm{n}=11)$. Thus, painful claws were equally painful without regard to claw of origin.

Locomotion $\mathrm{s}$ hereafter expressed on a scale from 1 to 3 . Locomotion scores 3,4 , and 5 were collapsed into a single score (3). This was valid because the 1 to 3 locomotion scale distinguished visibly normal locomotion (scores 1 and 2) from visibly abnormal locomotion (scores $\geq 3$ ). Table 5 gives the summary statistics for the pain responses for lateral and medial claws grouped by locomotion scores. Clearly, the means decreased ( $P$ $<0.001$ ) for lateral claws with higher locomotion scores, whereas there was no trend for the medial claws. The data showed a remarkable symmetry in pain behavior between left hind (LH) and right hind (RH) limbs in that the mean PICLAW for left and right lateral and medial claws coincided $(P=0.093,0.221$, and 0.231 , respectively). Clearly, lateral rather than medial claw pain dominated the limb locomotion score.

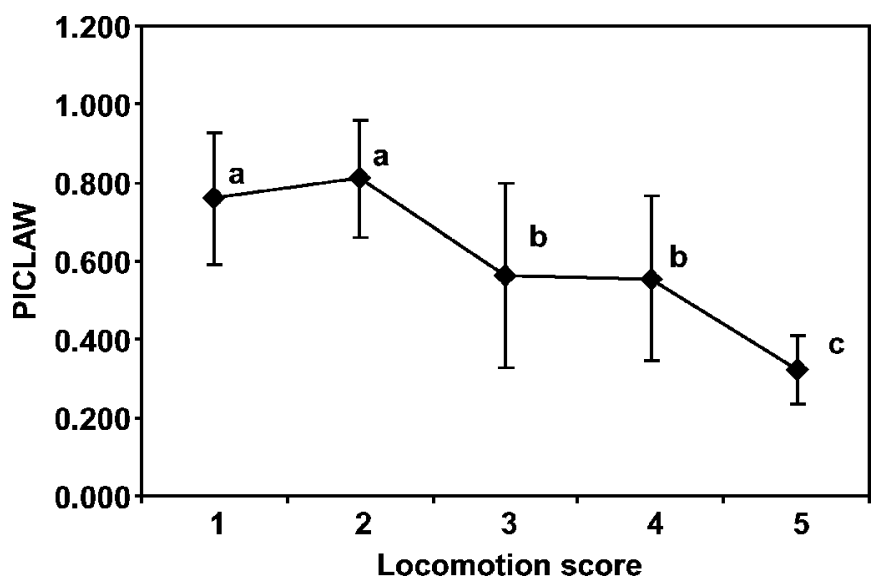

Figure 1. The relationship of claw pain index (PICLAW, dimensionless) to locomotion score within all painful lateral claws. Data are shown as mean \pm SD $(\mathrm{n}=183)$. ${ }^{\mathrm{a}-\mathrm{c}}$ Data points with different letters differed $(P<0.05)$. 
Table 5. Summary statistics for PICLAW ${ }^{1}$ by locomotion score and by claw for right and left limbs

\begin{tabular}{|c|c|c|c|c|c|c|c|c|}
\hline \multirow{2}{*}{$\begin{array}{l}\text { Locomotion } \\
\text { score }\end{array}$} & \multicolumn{4}{|c|}{ Lateral claw } & \multicolumn{4}{|c|}{ Medial claw } \\
\hline & $\mathrm{n}$ & Mean & $\mathrm{SD}$ & $\mathrm{CV}(\%)$ & $\mathrm{n}$ & Mean & $\mathrm{SD}$ & $\mathrm{CV}(\%)$ \\
\hline \multicolumn{9}{|l|}{ Left hind limb } \\
\hline 1 & 180 & $0.944^{\mathrm{a}}$ & 0.131 & 13.9 & 180 & $0.998^{\mathrm{a}}$ & 0.015 & 1.5 \\
\hline 2 & 32 & $0.908^{\mathrm{a}}$ & 0.162 & 17.8 & 32 & $0.984^{\mathrm{a}}$ & 0.051 & 5.2 \\
\hline 3 & 50 & $0.681^{\mathrm{b}}$ & 0.285 & 41.8 & 50 & $0.998^{\mathrm{a}}$ & 0.012 & 1.2 \\
\hline Right hind limb & \multicolumn{4}{|c|}{ Lateral claw } & \multicolumn{4}{|c|}{ Medial claw } \\
\hline 1 & 152 & $0.967^{\mathrm{a}}$ & 0.105 & 10.9 & 152 & $0.995^{\mathrm{a}}$ & 0.025 & 2.5 \\
\hline 2 & 58 & $0.920^{\mathrm{a}}$ & 0.129 & 14.0 & 58 & $0.996^{\mathrm{a}}$ & 0.017 & 1.7 \\
\hline 3 & 52 & $0.668^{\mathrm{b}}$ & 0.283 & 42.4 & 52 & $0.989^{\mathrm{a}}$ & 0.041 & 4.2 \\
\hline
\end{tabular}

${ }^{\mathrm{a}, \mathrm{b}}$ Different superscripts indicate that values within columns differed significantly $(P<0.05)$.

${ }^{1}$ PICLAW = claw pain index (dimensionless).

\section{Changes in the Frequency of PICLAW Underscored the Relationship of Claw Pain to Limb Locomotion Score}

The negative relationship between PICLAW and ipsilateral limb locomotion score could arise from changes in the frequency and magnitude of claw pain across different levels of locomotion. Indeed, the frequency of painful lateral claws increased as the corresponding frequency of nonpainful lateral claws decreased with increasing locomotion score (Table $6 ; P<0.0001$ ). Similar observations occurred in the $\mathrm{LH}$ and $\mathrm{RH}$ limb for cows with unilaterally or bilaterally painful claws. Greater proportions of painful claws were associated with lameness and greater proportions of nonpainful claws were associated with a lack of lameness. Nevertheless, painful claws were not excluded from sound limbs because painful claws ipsilateral to sound limbs occurred on both LH and RH limbs for cows with painful claws on one or both hind limbs (Table 6).

\section{Effect of Locomotion Score on the Magnitude of Contralateral PICLAW Within Contralateral Limb Locomotion Score}

We determined whether there was a concomitant effect of locomotion score in one limb upon PICLAW in the contralateral limb. Table 7 shows the summary statistics for 262 PICLAW of the LH lateral claw (PICLAW_LH) across RH locomotion within each level of LH locomotion score. As expected, mean PICLAW_LH decreased $(P<0.001, P<0.0024$, and $P<$ 0.0033, respectively) within each level of RH locomotion score, whereas no obvious trend existed across $\mathrm{RH}$ locomotion scores. That is, within each group of cows receiving the same RH locomotion score, there was a negative association between the LH claw pain response and LH locomotion score. The analysis (Table 7) showed no effect of RH locomotion on PICLAW_LH within LH locomotion scores of 2 and 3; however, there was an effect of RH locomotion score on PICLAW_LH within LH locomotion score of 1 . Corresponding results and ANOVA for the PICLAW in the right hind limb (PICLAW_RH) are given in Table 8. As expected, mean PICLAW_RH decreased within each level of LH locomotion score $(P \leq 0.0001,<0.0129$, and $\leq 0.0001$, respectively), whereas no obvious trend in PICLAW_RH existed across the 3 levels of LH locomotion score (Table 8). That is, within each group of cows receiving the same LH locomotion score, there was a negative association between the PICLAW_RH response and RH locomotion score. However, all 3 ANOVA results (Table 8) indicated a lack of effect of LH locomotion score on PICLAW_RH

Table 6. Frequency of claw pain by locomotion score for left hind (LH) and right hind (RH) limbs ${ }^{1}$

\begin{tabular}{|c|c|c|c|c|c|c|c|c|}
\hline & \multicolumn{4}{|c|}{ LH limb locomotion score } & \multicolumn{4}{|c|}{ RH limb locomotion score } \\
\hline & 1 & 2 & $\geq 3$ & Total & 1 & 2 & $\geq 3$ & Total \\
\hline PICLAW $^{2}$ & $\mathrm{n}(\%)$ & $\mathrm{n}(\%)$ & $\mathrm{n}(\%)$ & & $\mathrm{n}(\%)$ & $\mathrm{n}(\%)$ & $\mathrm{n}(\%)$ & \\
\hline 1.0 & $130(86)$ & $11(7)$ & $11(7)$ & 152 & $124(76)$ & 28 (17) & $12(7)$ & 164 \\
\hline$<1.0$ & $50(45)$ & 21 (19) & 39 (35) & 110 & $28 \quad(29)$ & 30 & 40 & 98 \\
\hline Total & 180 & 32 & 50 & 262 & 152 & 58 & 52 & 262 \\
\hline
\end{tabular}

${ }^{1}$ Significance of $\chi^{2}$ test for the association between locomotion and claw pain for LH was $P<0.0001\left(\chi^{2}=\right.$ 48.88) and for $\mathrm{RH}$ was $P<0.0001\left(\chi^{2}=63.16\right)$.

${ }^{2}$ PICLAW $=$ claw pain index (dimensionless). 
Table 7. The relationship between right hind limb $(\mathrm{RH})$ locomotion and the magnitude of pain in the left hind (LH) limb (PICLAW_LH) ${ }^{1}$ by LH locomotion

\begin{tabular}{|c|c|c|c|c|c|c|c|c|c|c|}
\hline \multirow{2}{*}{$\begin{array}{l}\text { PICLAW_LH: } \\
\text { LH locomotion } \\
\text { score }\end{array}$} & & \multicolumn{3}{|c|}{$\mathrm{RH}$ locomotion } & \multirow[b]{2}{*}{ Source } & \multirow[b]{2}{*}{$\mathrm{df}$} & \multirow[b]{2}{*}{ SS } & \multirow[b]{2}{*}{ MS } & \multirow[b]{2}{*}{$F$-value } & \multirow[b]{2}{*}{$P$-value } \\
\hline & & 1 & 2 & 3 & & & & & & \\
\hline \multirow[t]{3}{*}{1} & $\mathrm{n}$ & 109 & 36 & 35 & & & & & & \\
\hline & Mean & $0.948^{\mathrm{a}}$ & $0.901^{\mathrm{ab}}$ & $0.857^{\mathrm{b}}$ & Model & 2 & 0.238 & 0.119 & 4.4 & 0.014 \\
\hline & SD & 0.140 & 0.173 & 0.218 & Error & 177 & 4.783 & 0.027 & - & - \\
\hline \multirow[t]{3}{*}{2} & $\mathrm{n}$ & 13 & 10 & 9 & & & & & & \\
\hline & Mean & $0.878^{\mathrm{a}}$ & $0.740^{\mathrm{a}}$ & $0.861^{\mathrm{a}}$ & Model & 2 & 0.120 & 0.060 & 1.15 & 0.331 \\
\hline & SD & 0.172 & 0.318 & 0.177 & Error & 29 & 1.515 & 0.052 & & - \\
\hline \multirow[t]{3}{*}{3} & $\mathrm{n}$ & 30 & 12 & 8 & & & & & & \\
\hline & Mean & $0.610^{\mathrm{a}}$ & $0.640^{\mathrm{a}}$ & $0.564^{\mathrm{a}}$ & Model & 2 & 0.027 & 0.013 & 0.15 & 0.857 \\
\hline & SD & 0.320 & 0.279 & 0.231 & Error & 47 & 4.193 & 0.089 & - & - \\
\hline
\end{tabular}

${ }^{\mathrm{a}, \mathrm{b}}$ Different superscripts indicate that values within rows differ significantly $(P<0.05)$.

${ }^{1}$ PICLAW_LH is dimensionless.

within RH locomotion score. Together, the data showed an inconsistent and weak effect of limb locomotion score in one limb on the magnitude of PICLAW in the contralateral limb. Similar results were observed within the data set of painful claws rather than all claws (data not shown). Results were confirmed when we determined the correlation between the magnitude of PICLAW in one hind limb with that of the opposite hind limb. The correlation coefficient was $0.30(P<0.05)$ for the data set of all PICLAW responses. The correlation coefficient was $0.34(P<0.05)$ when the data set was restricted to PICLAW of bilaterally painful animals $(\mathrm{n}=61)$. Both analytic methodologies demonstrated a low relationship of claw pain in one limb to that of the opposite limb. The results must be evaluated cautiously because the distribution of the pain response data was highly skewed with a considerable amount of heterogeneity (unequal standard deviations) among the groups.

\section{The Effect of Locomotion Scores in One Limb on the Frequency of Painful Claws in the Contralateral Limb}

Even though many types of claw problems appear with a bilateral lesion distribution, we determined that locomotion disturbances in one limb had an inconsistent effect on the magnitude of PICLAW in the contralateral limb. Next, we determined if locomotion disturbances in one hind limb might affect the frequency of painful claws in the contralateral hind limb. The frequency of painful LH claws (PICLAW_LH $<1$ ) increased with increasing RH locomotion score $(P \geq 0.0213$; Table 9 ). Nevertheless, no such relationship appeared between the frequency of painful RH claws (PICLAW_RH $<1)$ and increasing LH locomotion score $(P \geq 0.1302$; Table 10). Thus, in accord with the magnitude of pain, the relationship between limb locomotion score and the frequency of claw pain in the contralateral limb was low and inconsistent.

\section{The Magnitude of PICLAW for Claws Associated with Unilateral and Bilaterally Painful Limbs Within 3 Levels of Locomotion Score}

The PICLAW was 1 (no pain) in many of the limbs with locomotion score 1 in either LH $(n=130$; Table $11)$ or $\mathrm{RH}(\mathrm{n}=124$; Table 12) limbs. Some cows ( $\mathrm{n}=$ 23 ) with $\mathrm{LH}$ or $\mathrm{RH}$ locomotion scores $\geq 3(\mathrm{n}=82)$ also had PICLAW = 1 in claws ipsilateral to the lame limb

Table 8. The relationship between left hind (LH) limb locomotion and the magnitude of pain in the right hind $(\mathrm{RH})$ limb (PICLAW_RH) by RH locomotion

\begin{tabular}{|c|c|c|c|c|c|c|c|c|c|c|}
\hline \multirow{2}{*}{$\begin{array}{l}\text { PICLAW_RH: } \\
\text { RH locomotion } \\
\text { group }\end{array}$} & & \multicolumn{3}{|c|}{ LH locomotion } & \multirow[b]{2}{*}{ Source } & \multirow[b]{2}{*}{$\mathrm{df}$} & \multirow[b]{2}{*}{ SS } & \multirow[b]{2}{*}{ MS } & \multirow[b]{2}{*}{$F$-value } & \multirow[b]{2}{*}{$P$-value } \\
\hline & & 1 & 2 & 3 & & & & & & \\
\hline \multirow[t]{3}{*}{1} & $\mathrm{n}$ & 109 & 13 & 30 & & & & & & \\
\hline & Mean & $0.955^{\mathrm{a}}$ & $0.981^{\mathrm{a}}$ & $0.906^{\mathrm{a}}$ & Model & 2 & 0.073 & 0.037 & 2.02 & 0.136 \\
\hline & SD & 0.133 & 0.053 & 0.163 & Error & 149 & 2.705 & 0.018 & - & - \\
\hline \multirow[t]{3}{*}{2} & $\mathrm{n}$ & 36 & 10 & 12 & & & & & & \\
\hline & Mean & $0.897^{\mathrm{a}}$ & $0.869^{\mathrm{a}}$ & $0.881^{\mathrm{a}}$ & Model & 2 & 0.007 & 0.003 & 0.14 & 0.872 \\
\hline & SD & 0.157 & 0.168 & 0.140 & Error & 55 & 1.338 & 0.024 & - & - \\
\hline \multirow[t]{3}{*}{3} & $\mathrm{n}$ & 35 & 9 & 8 & & & & & & \\
\hline & Mean & $0.631^{\mathrm{ab}}$ & $0.791^{\mathrm{a}}$ & $0.491^{\mathrm{b}}$ & Model & 2 & 0.384 & 0.192 & 2.65 & 0.081 \\
\hline & SD & 0.282 & 0.188 & 0.284 & Error & 49 & 3.552 & 0.072 & - & - \\
\hline
\end{tabular}

${ }^{\mathrm{a}, \mathrm{b}}$ Different superscripts indicate that values within rows differ significantly $(P<0.05)$.

${ }^{1}$ PICLAW_RH is dimensionless. 
Table 9. The relationship between right hind $(\mathrm{RH})$ locomotion score and the frequency of pain in the left hind (LH) limb (PICLAW_LH) ${ }^{1}$

\begin{tabular}{llcccc}
\hline & & \multicolumn{4}{c}{ RH locomotion } \\
\cline { 3 - 6 } PICLAW_LH $^{2}$ & & 1 & 2 & 3 & Total \\
\hline 1.0 & $\mathrm{n}$ & 99 & 29 & 24 & 152 \\
& $(\%)$ & $(65)$ & $(19)$ & $(16)$ & $(100)$ \\
$<1.0$ & $\mathrm{n}$ & 53 & 29 & 28 & 110 \\
& $(\%)$ & $(48)$ & $(26)$ & $(25)$ & $(100)$
\end{tabular}

${ }^{1}$ The significance of the $\chi^{2}$ test for the association between $\mathrm{RH}$ locomotion and claw pain (PICLAW_LH) was $P=0.0213\left(\chi^{2}=7.69\right)$.

${ }^{2} \mathrm{PICLAW}$ LH is dimensionless.

(Tables 11 and 12). Nine of these cows were diagnosed with painful arthritis of the metatarsal, femoral-tibial, or interphalangeal joints; 2 showed very abnormal locomotion most likely misdiagnosed as lameness; 2 demonstrated mild to moderate white line disease; and one had a double sole, one a moderately severe sole ulceration, and 3 had various levels of sole hemorrhage localized to region 4 . No visible lesions were recorded in 5 of these cows. Of the visible locomotion problems not affiliated with painful claws, $48 \%$ were explained by problems other than claw lesions.

Painful claws occurred ipsilateral or contralateral, or both, to locomotion score 1 and locomotion score $\geq 2$ for LH or RH limbs (Tables 11 and 12). The magnitude of PICLAW for painful claws did not differ between locomotion scores 1 and 2 in the LH or RH limbs. A lower magnitude $(P<0.001)$ of PICLAW (higher levels of pain) was displayed by claws on locomotion score $\geq 3$ hind limbs than on limbs with scores $\leq 2$. Painful claws $(\mathrm{n}=78)$ occurred on sound limbs (score $1, \mathrm{n}=332)$ with a pain index $(0.72 \pm 0.02)$ indicative of less pain $(P<$ $0.005)$ than the pain index $(0.61 \pm 0.02)$ of painful claws $(\mathrm{n}=130)$ on limbs with locomotion disturbances (scores 2 and $3, \mathrm{n}=192$ ) Moreover, painful claws ( $\mathrm{n}=129)$ occurred on limbs lacking visible locomotion disturbances (score 1 and 2$)$ with a pain index $(0.74 \pm 0.02)$ indicative of less pain $(P<0.005)$ than the pain index $(0.51 \pm 0.03)$ of painful claws $(\mathrm{n}=79)$ on limbs with

Table 10. The relationship between left hind (LH) locomotion score and the frequency of pain in the right hind $(\mathrm{RH})$ limb (PICLAW_RH ${ }^{1}$

\begin{tabular}{llcccc}
\hline & & \multicolumn{4}{c}{ LH locomotion } \\
\cline { 3 - 6 } PICLAW_RH $^{2}$ & & 1 & 2 & 3 & Total \\
\hline 1.0 & $\mathrm{n}$ & 120 & 17 & 27 & 164 \\
& $(\%)$ & $(73)$ & $(10)$ & $(16)$ & $(100)$ \\
$<1.0$ & $\mathrm{n}$ & 60 & 15 & 23 & 98 \\
& $(\%)$ & $(61)$ & $(15)$ & $(23)$ & $(100)$ \\
\hline
\end{tabular}

${ }^{1}$ The significance of the $\chi^{2}$ test for the association between LH locomotion and claw pain (PICLAW_RH) was $P=0.1302\left(\chi^{2}=4.08\right)$.

${ }^{2}$ PICLAW_RH is dimensionless.
Table 11. The PICLAW_LH ${ }^{1}$ by left hind (LH) limb locomotion score for painful claws in unilateral and bilateral lameness

\begin{tabular}{|c|c|c|c|c|c|}
\hline \multicolumn{2}{|c|}{$\begin{array}{l}\text { PICLAW_LH } \\
\text { Pain response }\end{array}$} & & \multicolumn{3}{|c|}{ LH locomotion } \\
\hline $\mathrm{LH}$ & $\mathrm{RH}$ & & 1 & 2 & 3 \\
\hline \multirow[t]{3}{*}{ No } & No & $\mathrm{n}$ & 98 & 9 & 8 \\
\hline & & Mean & $1.0^{\mathrm{a}}$ & $1.0^{\mathrm{a}}$ & $1.0^{\mathrm{a}}$ \\
\hline & & SD & 0 & 0 & 0 \\
\hline \multirow[t]{3}{*}{ No } & Yes & $\mathrm{n}$ & 32 & 2 & 3 \\
\hline & & Mean & $1.0^{\mathrm{a}}$ & $1.0^{\mathrm{a}}$ & $1.0^{\mathrm{a}}$ \\
\hline & & SD & 0 & 0 & 0 \\
\hline \multirow[t]{3}{*}{ Yes } & No & $\mathrm{n}$ & 22 & 8 & 19 \\
\hline & & Mean & $0.749^{\mathrm{a}}$ & $0.821^{\mathrm{a}}$ & $0.494^{\mathrm{b}}$ \\
\hline & & SD & 0.183 & 0.197 & 0.268 \\
\hline \multirow[t]{3}{*}{ Yes } & Yes & $\mathrm{n}$ & 28 & 13 & 20 \\
\hline & & Mean & $0.688^{\mathrm{a}}$ & $0.691^{\mathrm{a}}$ & $0.504^{\mathrm{b}}$ \\
\hline & & $\mathrm{SD}$ & 0.223 & 0.257 & 0.202 \\
\hline
\end{tabular}

${ }^{\mathrm{a}, \mathrm{b}}$ Different superscripts indicate that values within rows differ significantly $(P<0.05)$.

${ }^{1}$ PICLAW_LH $=$ pain response in LH claw (dimensionless).

visible locomotion disturbances (score 3). Thus, claw pain occurred in sound and visibly lame limbs, but substantially greater reductions in normal PICLAW (PICLAW $=1$ ) were associated with visible changes in locomotion (score 3 ). The magnitude of claw pain in claws of animals with bilaterally painful claws was not different from the magnitude of pain in claws of animals with unilaterally painful claws.

\section{DISCUSSION}

Objective, continuous measures of claw and soft tissue pain were obtained with hoof testers and an algometer. The technique for detection of claw pain was affected by the state of claw trimming. Results showed

Table 12. The PICLAW_RH ${ }^{1}$ by right hind $(\mathrm{RH})$ locomotion score for painful claws in unilateral and bilateral lameness

\begin{tabular}{|c|c|c|c|c|c|}
\hline \multicolumn{2}{|c|}{$\begin{array}{l}\text { PICLAW_RH } \\
\text { Pain response }\end{array}$} & & \multicolumn{3}{|c|}{$\mathrm{RH}$ locomotion } \\
\hline $\mathrm{LH}$ & $\mathrm{RH}$ & & 1 & 2 & 3 \\
\hline \multirow[t]{3}{*}{ No } & No & $\mathrm{n}$ & 89 & 17 & 9 \\
\hline & & Mean & $1^{\mathrm{a}}$ & $1^{\mathrm{a}}$ & $1^{\mathrm{a}}$ \\
\hline & & SD & 0 & 0 & 0 \\
\hline \multirow[t]{3}{*}{ No } & Yes & $\mathrm{n}$ & 10 & 12 & 15 \\
\hline & & Mean & $0.759^{\mathrm{a}}$ & $0.800^{\mathrm{a}}$ & $0.543^{\mathrm{b}}$ \\
\hline & & SD & 0.169 & 0.157 & 0.219 \\
\hline \multirow[t]{3}{*}{ Yes } & No & $\mathrm{n}$ & 35 & 11 & 3 \\
\hline & & Mean & $1^{\mathrm{a}}$ & $1^{\mathrm{a}}$ & $1^{\mathrm{a}}$ \\
\hline & & $\mathrm{SD}$ & 0 & 0 & 0 \\
\hline \multirow[t]{3}{*}{ Yes } & Yes & $\mathrm{n}$ & 18 & 18 & 25 \\
\hline & & Mean & $0.691^{\mathrm{a}}$ & $0.774^{\mathrm{a}}$ & $0.519^{b}$ \\
\hline & & SD & 0.195 & 0.153 & 0.224 \\
\hline
\end{tabular}

${ }^{a, b}$ Different superscripts indicate that values within rows differ significantly $(P<0.05)$.

${ }^{1} \mathrm{PICLAW} \_\mathrm{RH}=$ pain response in $\mathrm{RH}$ claw (dimensionless). 
that trimming in combination with claw lesions, but not trimming per se, affected pain detection. Removal of excess hoof horn from claws with lesions apparently enhanced pain receptor stimulation by external pressure.

The data demonstrated that disturbances in limb locomotion were affected by the frequency and the magnitude of pain in claws. Both frequency and magnitude of claw pain increased with the level of locomotion disturbances in the ipsilateral limb. Both effects were most evident in the lateral claw and least evident in the medial claw due to wide differences in lesion and pain distribution between claws. Widening $\mathrm{CV}$ at lower PICLAW (greater claw pain) underscored greater variations in pain associated with greater disturbances in locomotion. The reason for this association was unclear, but different levels of pain or variation in nociceptive threshold (Whay et al., 1998) could produce different levels of pain within a given level of locomotion. Several limbs with clearly visible locomotion disturbances $(\mathrm{n}=$ 23) lacked claw pain, but possessed sufficient arthritis $(\mathrm{n}=9)$ of an interphalangeal, tibial-tarsal, or tarsalmetatarsal joint to explain the lameness. Moreover, 2 additional discrepancies were explained by abnormalities in limb movement that were scored as lame and displayed proprioceptive deficits. Still, white line disease $(n=2)$, sole hemorrhage $(n=3)$, sole ulceration $(\mathrm{n}=1)$, or double sole $(\mathrm{n}=1)$ were discovered on claws in association with no apparent pain upon claw compression. The explanation for lameness in these limbs was unclear. Possibly perception of pain triggered by claw compression (external compression) might be different from perception triggered by forces generated during impact and active phases of weight bearing.

The lack of medial claw pain was in accord with the low frequency of medial claw lesions reported in this and other studies (Murray et al., 1996). Indeed, the medial claw fortuitously provided an ideal internal control against which lateral claw responses could be evaluated. Clearly, lateral claw pain drives limb locomotion because the frequency of pain was nearly 6 -fold greater in lateral compared with medial claws. Differences in the frequency of lateral and medial claw pain did not translate into differences in magnitude of claw pain because lesion pain was similar in medial and lateral claws. This suggested that the 30:70 ratio of weight bearing in medial to lateral claws (Van der Tol et al., 2004) increased the frequency, but not necessarily the magnitude, of pain associated with lesions in lateral claws. The paucity of medial claw pain may serve to temper the discomfort of lateral claw overgrowth and pain. Cows rotate the claws and hind limb laterally off the vertical with increasing lameness in an attempt to shift weight-bearing toward the medial claw (van
Amstel and Shearer, 2006). Our pain measurements are in accord with this behavior, showing that the medial claw could afford a real respite from lateral claw pain during locomotion.

Subclinical claw lesions were described in other surveys (Manske et al., 2002; Somers et al., 2003) as lesions that appeared in the absence of locomotion disturbances. Our data extended these observations and showed, for the first time, that a relatively high frequency of painful lateral claws (37.2\%) occurred on limbs with normal locomotion score. Moreover, the magnitude of the PICLAW (0.718 to 0.725) displayed by painful lateral claws on sound limbs was greater than that of the PICLAW (0.616 to 0.618) associated with locomotion score $\geq 3$ limbs. The findings are consistent in that the magnitude of the PICLAW of subclinically painful claws should be greater than that of PICLAW of painful claws associated with locomotion disturbances. The data showed that substantial levels of pain occurred in claws associated with normal locomotion. The threshold of claw pain decreased nearly $30 \%$ below normal before the onset of visible disturbances of locomotion. We concluded that the frequency of subclinical claw pain represented an important underlying problem in this cow population because a substantial magnitude of pain occurred in the absence of lameness. The type, severity, and number of lesions affiliated with this type of claw pain remain the subject of an ongoing investigation, but the results suggested that the cows possessed a tremendous ability to adapt to claw pain.

One could argue that the association of painful claws with sound (locomotion score 1) limbs represented falsepositive responses rather than subclinical pain. A falsepositive response could arise either as a hyperactive response by nervous cows to claw compression or the application of excessive force or pressure to normal claws. To address hyperreactivity, all cows were introduced to hoof compression with low pressures of 100 to $150 \mathrm{~N} / \mathrm{cm}^{2}$ applied 4 to 5 times on every claw before test application. Thereafter, all tests using maximum pressures of $459.74 \mathrm{~N} / \mathrm{cm}^{2}$ were started on the medial claw. Because the medial claws were rarely problematic, they provided a convenient internal control for the response to claw compression. We assumed that if the cow did not react to compression of the medial claw with a pressure of $459.74 \mathrm{~N} / \mathrm{cm}^{2}$, then any response observed on the lateral claw was attributable to pain rather than hyperreactive responses of nervous animals. In those cases in which painful responses were associated with sound limb locomotion scores, we repeated a second set of compression tests on the medial and lateral claws to ensure reproducibility. These precautionary measures minimized the chance of confusing reactivity of hyperactive, nervous animals with le- 
gitimate responses to pain. Excessive compressive force rendering false positives seemed unlikely. The maximum compression force $(711.68 \mathrm{~N})$ applied along the axial-abaxial axis of the claw was $29.1 \%$ of the maximum vertical ground reaction force $(2,444 \mathrm{~N})$ acting on the claw during the stride (Van der Tol et al., 2003). The compression force generated pressures $(459.74 \mathrm{~N} /$ $\mathrm{cm}^{2}$ ) on regions 3 and 4 that were only 2.5 -fold greater than maximum pressures $\left(180 \mathrm{~N} / \mathrm{cm}^{2}\right)$ sustained by the claw during push off. Thus, the magnitude of the forces and pressures during compression were in range with those generated during the stance. Accordingly, it seems unlikely that excessive compression pressures triggered false pain responses. The conservative methodology and application of realistic pressure and force during compression are compelling reasons to regard low PICLAW on a sound limb (locomotion score 1) as evidence of subclinical pain.

Others established a positive, albeit low, correlation for the presence of lesions on both $\mathrm{LH}$ and $\mathrm{RH}$ hind limbs (Manske et al., 2002). Enevoldsen and Grohn (1991) found that multiple sole ulcerations occurred in 29.7 and $24.7 \%$ of first- and second or greater-lactation cows, respectively. In accordance with these findings, we found that the frequency of unilateral and bilateral painful events was 86/262 (32.8\%) and 61/262 (23.3\%), respectively. Manske et al. (2002) described a lesiondependent but wide range of correlation ( 0.26 to 0.76 ) for the occurrence of similar types of lesions between hind claws. In our investigation, correlation analysis indicated a low relationship for the magnitude of pain between the 2 hind limbs. The correlation for pain was closer to the lower correlation coefficients described for lesions by Manske et al. (2002). It seemed that pain or locomotion problems in one hind limb may have had little direct bearing on events in the opposite limb. Temporal observation will be necessary to determine if the pain events described herein represent a continuum of lesion progression or separate processes of lesion pathology. We emphasize that our analysis was performed on claws and limbs with a diverse array of claw lesions (Table 2) in a relatively small population of cows. In this light, laminitis produces bilateral pain and corium lamina damage (Thoefner et al., 2005) and predisposed claws to secondary sole ulceration and white line disease (Manske et al. 2002). Because the occurrence of sole ulceration was recognized as a bilateral claw problem (Enevoldsen and Grohn, 1991; reviewed in van Amstel and Shearer, 2006), we might expect to see a strong cross-limbed relationship for pain and locomotion disturbances, at least within sole ulceration. Larger data sets will provide sufficient power to reexamine crosslimbed relationships of the frequency and magnitude of claw pain within different lesion types and across lesion severity score.

\section{CONCLUSIONS}

The present report described the magnitude and frequency of pain using a novel technique to quantify objectively claw and soft tissue pain in the bovine foot. There was a strong effect of claw pain on ipsilateral but not contralateral, limb locomotion score for lateral but not medial claws. The difference stemmed from higher frequency of claw lesions in lateral compared with the medial claws. When present, the magnitude of pain in the medial claw was not different from that in the lateral claw. The relationship between pain and locomotion score was reduced by appearance of subclinical pain, inherent variability in locomotion presentation between animals, and undiagnosed upper limb and claw conditions affecting locomotion. Bilateral claw pain was evident in $23.3 \%$ of the commercial dairy cows, whereas unilateral claw pain was found in $32.8 \%$ of the cows. The remainder of the cows (43.9\%) showed no pain in either LH or RH claws. Subclinical pain was present in $37.2 \%$ of the lateral claws. Objective pain measurement may be valuable in defining the relationship of claw pain to various ground reaction forces, limb movement traits, and measures of left to right symmetry during modeling of lameness. Moreover, objective measures of pain may provide a more comprehensive cost analysis of lameness due to reduction in milk yield, reproductive dysfunction, and culling losses in modern dairy cattle.

\section{ACKNOWLEDGMENTS}

This research was supported by USDA-SBIR grants 2004-33610-14360 and 2005-03204. The authors are grateful for the valuable input and discussion from Alan Lefcourt.

\section{REFERENCES}

Clarkson, M. J., D. Y. Downham, W. B. Faull, J. W. Hughes, F. J. Manson, J. B. Merrit, R. D. Murray, W. B. Russel, J. E. Sutherst, and W. R. Ward. 1996. Incidence and prevalence of lameness in dairy cattle. Vet. Rec. 138:563-567.

Enevoldsen, C., and Y. T. Grohn. 1991. Sole ulcers in dairy cattle: Associations with season, cow characteristics, disease and production. J. Dairy Sci. 74:1284-1298.

Engel, B., G. Bruin, G. Andre, and W. Buist. 2003. Assessment of observer performance in a subjective scoring system: Visual classification of the locomotion of cows. J. Agric. Sci. 140:317-333.

Flower, F. C., D. J. Sanderson, and D. M. Weary. 2005. Hoof pathologies influence kinematic measures of dairy cow locomotion. J. Dairy Sci. 88:3166-3173.

Flower, F. C., and D. M. Weary. 2006. Effect of hoof pathologies on subjective assessments of dairy cow locomotion. J. Dairy Sci. 89:139-146. 
Holzhauer, M., H. Middelesch, C. J. M. Bartels, K. Frankena, E. N. Verhoeff, E. N. Noordhuizen-Stassen, and J. P. T. M. Noordhuizen. 2005. Assessing the repeatability and reproducibility of the Leg Score: A Dutch claw health scoring system for dairy cattle. Tijdschr. Diergeneerskd. 130:440-443.

Manske, T., J. Hultgren, and C. Bergsten. 2002. Prevalence and interrelationships of hoof lesions and lameness in Swedish dairy cows. Prev. Vet. Med. 54:247-263.

Murray, R. D., D. Y. Downham, M. J. Clarkson, W. B. Faull, J. W. Hughes, F. J. Manson, J. B. Merrit, W. B. Russel, J. E. Sutherst, and W. R. Ward. 1996. Epidemiology of lameness in dairy cattle: Description and analysis of foot lesions. Vet. Rec. 138:586-591.

NRC. 2001. Nutrient Requirements of Dairy Cattle. 7th ed. Natl. Acad. Sci., Washington, DC.

Rajkondawar, P. G., M. Liu, R. M. Dyer, N. K. Neerchal, U. Tasch, A. M. Lefcourt, B. Erez, and M. A. Varner. 2006. Comparison of models to identify lame cows based on locomotion and lesion scores, and limb movement variables. J. Dairy Sci. 89:4267-4275.

Scott, G. B. 1989. Changes in limb loading with lameness for a number of Friesian cattle. Br. Vet. J. 145:22-38.

Shearer, J., D. Anderson, W. Ayars, E. Belknap, S. Berry, C. Guard, K. Hoblet, E. Hovingh, G. Kirksey, A. Langill, A. Mills, D. Miskimins, J. Osterstock, R. Price, D. Prigel, A. Roussel, S. van Amstel, R. Wallace, J. Wasson, N. Cook, E. Garret, D. G. Hostetler, and L. Schugel. 2004. A record-keeping system for capture of lameness and foot-care information in cattle. Bovine Pract. 38:83-92.

Somers, J. G. C. J., K. Frankena, E. N. Noorhuizen-Stassen, and J. H. M. Metz. 2003. Prevalence of claw disorders in Dutch dairy cows exposed to several floor systems. J. Dairy Sci. 86:2082-2093.
Sprecher, D. J., D. E. Hosteler, and J. B. Kaneene. 1997. A lameness scoring system that uses posture and locomotion to predict dairy cattle reproductive performance. Theriogenology 47:1179-1187.

Thoefner, M. B., O. Wattle, C. C. Politt, K. R. French, and S. S. Nelson. 2005. Histopathology of oligofructose-induced acute laminitis in heifers. J. Dairy Sci. 88:2774-2782.

Toussaint-Raven, E. 1985. The principals of claw trimming. Symp. bovine lameness and orthopedics. Vet. Clin. North Am. Food Anim. Pract. 1:93-107.

van Amstel, S. R., and J. K. Shearer. 2006. Review of pododermititis circumscripta (ulceration of the sole) in dairy cows. J. Vet. Intern. Med. 20:805-811.

Van der Tol, P. P., J. H. Metz, E. N. Noordhuizen-Stassen, W. Back, C. R. Braam, and W. A. Weijss. 2003. The vertical ground reaction force and the pressure distribution on the claws of dairy cows while walking on a flat substrate. J. Dairy Sci. 86:2875-2883.

Van der Tol, P. P., S. S. van der Beek, J. H. Metz, E. N. NoordhuizenStassen, W. Back, C. R. Braam, and W. A. Weijs. 2004. The effect of preventive trimming on weight bearing and force balance on the claws of dairy cattle. J. Dairy Sci. 87:1732-1738.

Wells, S. J., A. M. Trent, W. E. Marsh, and R. A. Robinson. 1993. Prevalence and severity of lameness in lactating dairy cows in a sample of Minnesota and Wisconsin herds. J. Am. Vet. Med. Assoc. 202:78-82.

Whay, H. R., A. E. Watterman, and A. J. Webster. 1997. Associations between locomotion, claw lesions and nociceptive threshold in dairy heifers during the peripartum period. Vet. J. 154:155-161.

Zar, J. H. 1994. Biostatistical Analysis. 3rd ed. Prentice Hall, New Jersey. 